\title{
Clinical Profile of Patients Undergoing Laparoscopic Hysterectomy
}

\author{
Lakshmi Subburaj $^{1}$, Selvapriya Saravanan ${ }^{2}$, Raj Kumar ${ }^{3}$
}

\begin{abstract}
Background: Laparoscopic hysterectomy is a minimally invasive procedure with shorter operative time, decreased trauma, and less technical difficulty. However, the success of the procedure depends on various intrinsic and extrinsic factors. This study was done to evaluate the factors which influence the success of laparoscopic hysterectomy.

Materials and methods: This retrospective record-based cross-sectional study was carried out among 100 participants who underwent laparoscopic hysterectomy for various indications in our tertiary care hospital. The demographic and clinical profiles of these participants were recorded. Particulars related to the success of the surgery including duration of surgery and hospital stay, infections, and other complications were recorded.
\end{abstract}

Results: Our study showed that the duration of surgery and duration of hospital stay were significantly influenced by the parity. Multiparous women were more prone to longer duration of surgery and prolonged hospitalization. The observed difference was statistically significant ( $p$ $<0.05)$.

Conclusion: It is essential to develop a scoring mechanism by which each case can be selected or rejected for laparoscopic hysterectomy considering various parameters. This may be carried out by further exploratory research on identifying the key factors which influence the success of the procedure.

Keywords: Body mass index, Fibroid uterus, Laparoscopic hysterectomy, Parity.

Journal of South Asian Federation of Obstetrics and Gynaecology (2020): 10.5005/jp-journals-10006-1823

\section{INTRODUCTION}

Hysterectomy is a commonly performed surgical procedure for various gynecological conditions like dysfunctional uterine bleeding, fibroadenoma of the uterus, uterine malignancies, etc. Although hysterectomy is not indicated in the reproductive age group, it is essential to document substantial evidence suggestive and indicative of hysterectomy to avoid complications and adverse effects following the removal of the uterus. Thorough knowledge and understanding of the physiological and pathological states of the uterus are recommended before planning the surgery.

In most situations, hysterectomy is often coupled with bilateral oophorectomy and salpingectomy. One of the earliest hysterectomies was documented in 50 BC, performed by Themison Athens in $50 \mathrm{BC}$. $^{1}$ They were carried out very rarely, except on account of uterine prolapse and uterine inversion. This was later followed by abdominal hysterectomy for several indications including uterine cancers during the early part of the 20th century. With several advances in technology, laparoscopic hysterectomy, implemented in 1990, has improvised the techniques of hysterectomy and also has minimized various complications associated with the procedure. ${ }^{2}$ Laparoscopic assistance during hysterectomy has improved the quality of life of the patients, reduced the recuperation period, and facilitated easy convalescence.

Several factors have to be considered before planning a laparoscopic hysterectomy. One of the most important criteria is the size and weight of the uterus. When the uterus weighs greater than $1,000 \mathrm{~g}$, it is important to assess the flexibility of the anterior abdominal fossa, the residual intra-abdominal volume, ventilation pressure, and positioning of the patient to facilitate easy laparoscopic hysterectomy. ${ }^{3}$ Second, the obstetric history of the patient plays a major role in determining the outcomes. In most cases, the history of previous sections and multigravida women
${ }^{1}$ Department of Obstetrics and Gynecology, NTC Hospitals, Madurai, Tamil Nadu, India

${ }^{2}$ Department of Obstetrics and Gynecology, Spring Fertility Fetocare, Nagercoil, Tamil Nadu, India

${ }^{3}$ Department of Surgical Gastroenterology, NTC Hospitals, Madurai, Tamil Nadu, India

Corresponding Author: Lakshmi Subburaj, Department of Obstetrics and Gynecology, NTC Hospitals, Madurai, Tamil Nadu, India, Phone: +919843150092, e-mail: lakmisubburaj@gmail.com

How to cite this article: Subburaj L, Saravanan S, Kumar R. Clinical Profile of Patients Undergoing Laparoscopic Hysterectomy. J South Asian Feder Obst Gynae 2020;12(5):277-280.

Source of support: Nil

Conflict of interest: None

are said to have difficulty in maneuvering the uterus because of the increase in the muscle layers and the bulge of the uterus. In addition, the body mass index of the patient directly translates to the presence of extra fat tissue deposition in the abdominal region and this will add on to the uterine bulk, resulting in intraoperative and postoperative complications. ${ }^{4}$

The duration of hysterectomy plays a major role in determining the success of the procedure. This duration is in turn affected by various internal and external factors. There is a need to explore the morbidity factors associated with successful and unsuccessful outcomes following laparoscopic hysterectomy. This will create an insight into the pattern of presentation of women in whom laparoscopic hysterectomy is indicative. In addition, it will also help in identifying predictive risk factors which can be used as a guide for deciding on the type of surgery and its outcomes.

(c) Jaypee Brothers Medical Publishers. 2020 Open Access This article is distributed under the terms of the Creative Commons Attribution 4.0 International License (https://creativecommons.org/licenses/by-nc/4.0/), which permits unrestricted use, distribution, and non-commercial reproduction in any medium, provided you give appropriate credit to the original author(s) and the source, provide a link to the Creative Commons license, and indicate if changes were made. The Creative Commons Public Domain Dedication waiver (http://creativecommons.org/publicdomain/zero/1.0/) applies to the data made available in this article, unless otherwise stated. 


\section{Objectives}

This study was carried out to evaluate the clinical profile of patients undergoing laparoscopic hysterectomy.

\section{Materials and Methods}

\section{Study Setting and Participants}

This retrospective record-based cross-sectional study was carried out in the Department of Obstetrics and Gynecology of our tertiary care hospital for a period of one year between July 2018 and July 2019. All the patients who underwent laparoscopic hysterectomy during this study period were included in the study. A total of 100 women participated in this study.

\section{Ethical Approval and Informed Consent}

Approval was obtained from the Institutional Ethics Committee before the commencement of the study. Each participant was explained and detail about the study and informed consent was obtained before the data collection.

\section{Data Collection}

A structured proforma was used to obtained information regarding the demographic characteristics of the patients. Information regarding the laparoscopic hysterectomy was obtained from the medical case records regarding the type, duration of surgery, and requirements of blood transfusion. History regarding postoperative complications including the duration of hospital stay history of any infections was also recorded. Body mass index was calculated and categorized based on the WHO classification of body mass index for Asians and Indians. ${ }^{5}$

\section{Data Analysis}

Data were entered and analyzed using SPSS version 21 software. The clinical profile of the patients was expressed in percentages. The complications related to laparoscopic hysterectomy and the correlation of these complications with risk factors were analyzed using the Chi-square test. A $p$ value $<0.05$ was considered statistically significant.

\section{Results}

This study was carried out among 100 participants who underwent a laparoscopic hysterectomy. The majority of the participants were aged $35-50$ years (50\%) and were overweight (40\%). Most women were multiparous (80\%) and the fibroid uterus was the most common indication for surgery (39\%) (Table 1).

Total laparoscopic hysterectomy with bilateral salpingooophorectomy (TLH with BSO) was the most common type of procedure (58\%) and the surgery lasted for 60-120 minutes in 70\% of the participants. Blood transfusion was required in $15 \%$ of the participants (Table 2).

The majority of the participants stayed in the hospital for 2 to 5 days (77\%) and postoperative complications (adhesions) were highest in the participant group accounting for $42 \%$. Resuturing was required in $3 \%$ of the participants (Table 3 ). Histopathological diagnosis confirmed the presence of fibroid uterus in the majority of the participants (Fig. 1).

Our study showed that the duration of surgery and duration of hospital stay were significantly influenced by the parity. Multiparous women were more prone to longer duration of surgery and
Table 1: Background characteristics of the study participants

\begin{tabular}{|c|c|c|c|}
\hline S. no. & Characteristics & $\begin{array}{l}\text { Frequency } \\
(n=100)\end{array}$ & Percentage \\
\hline \multirow[t]{4}{*}{1} & Age (in years) & & \\
\hline & $<35$ & 29 & 29 \\
\hline & $35-50$ & 50 & 50 \\
\hline & $>50$ & 21 & 21 \\
\hline \multirow[t]{5}{*}{2} & Body mass index $\left(\mathrm{kg} / \mathrm{m}^{2}\right)$ & & \\
\hline & Underweight $(<18.00)$ & 1 & 1 \\
\hline & Normal (18.00-24.99) & 37 & 37 \\
\hline & Overweight (25.00-29.99) & 40 & 40 \\
\hline & Obese $(>30.00)$ & 22 & 22 \\
\hline \multirow[t]{4}{*}{3} & Parity & & \\
\hline & Nulliparous & 4 & 4 \\
\hline & Primi & 16 & 16 \\
\hline & Multiparous & 80 & 80 \\
\hline \multirow[t]{6}{*}{4} & Indication for surgery & & \\
\hline & Abnormal uterine bleeding & 33 & 33 \\
\hline & Fibroid uterus & 39 & 39 \\
\hline & Large fibroids & 4 & 4 \\
\hline & Others & 13 & 13 \\
\hline & More than one indication & 11 & 11 \\
\hline \multirow[t]{8}{*}{5} & History of previous surgeries & & \\
\hline & None & 48 & 48 \\
\hline & Single LSCS & 8 & 8 \\
\hline & $>1 \mathrm{LSCS}$ & 17 & 17 \\
\hline & Myomectomy & 1 & 1 \\
\hline & Multiple surgeries & 4 & 4 \\
\hline & Tubectomy & 4 & 4 \\
\hline & Others & 18 & 18 \\
\hline
\end{tabular}

Table 2: Intraoperative particulars related to laparoscopic hysterectomy

\begin{tabular}{|c|c|c|c|}
\hline S. no. & Characteristics & $\begin{array}{l}\text { Frequency } \\
(n=100)\end{array}$ & Percentage \\
\hline \multirow[t]{4}{*}{1} & Type of surgery & & \\
\hline & $\begin{array}{l}\text { Total laparoscopic } \\
\text { hysterectomy (TLH) }\end{array}$ & 33 & 33 \\
\hline & $\begin{array}{l}\text { Total laparoscopic } \\
\text { hysterectomy with bilateral } \\
\text { salpingo-oophorectomy (TLH } \\
\text { with BSO) }\end{array}$ & 58 & 58 \\
\hline & $\begin{array}{l}\text { Total laparoscopic hysterec- } \\
\text { tomy with other surgeries }\end{array}$ & 9 & 9 \\
\hline \multirow[t]{4}{*}{2} & Duration of surgery (in minutes) & & \\
\hline & $<60$ & 25 & 25 \\
\hline & $60-120$ & 70 & 70 \\
\hline & $>120$ & 5 & 5 \\
\hline \multirow[t]{3}{*}{3} & Additional procedures & & \\
\hline & Present & 15 & 15 \\
\hline & Absent & 85 & 85 \\
\hline \multirow[t]{3}{*}{4} & Need for blood transfusion & & \\
\hline & Present & 17 & 17 \\
\hline & Absent & 83 & 83 \\
\hline
\end{tabular}


prolonged hospitalization. The observed difference was statistically significant $(p<0.05)$ (Table 4).

\section{Discussion}

Laparoscopic hysterectomy is a minimally invasive procedure with shorter operative time, decreased trauma, and less technical difficulty. In most cases, the hysterectomy is complete in itself with the removal of the uterine cavity, especially when the uterus is removed through the vaginal route. Patients following laparoscopic hysterectomy suffer from reduced blood loss, shorter hospital stay, and quicker resumption to normal activities, thereby improving the quality of life and few abdominal wall infections as compared to abdominal hysterectomy. ${ }^{6}$ However, the surgeons need to have the technical expertise and adequate training to surpass the barriers associated with technical difficulties of performing this procedure.

In ideal operating conditions, the patient is usually put on a lithotomy position and the uterine manipulator is inserted. Following this abdominal entry is made through a $5-\mathrm{mm}$ skin incision at palmar's point and two 5-mm trocars are placed lateral to the rectus abdominis muscles. This is followed by cauterization and cutting the round ligament, then proceeded with IP or ovarian depending upon the decision to remove the ovary. The next step

Table 3: Postoperative particulars related to laparoscopic hysterectomy

\begin{tabular}{|c|c|c|c|}
\hline S. no. & Characteristics & $\begin{array}{l}\text { Frequency } \\
(n=100)\end{array}$ & Percentage \\
\hline \multirow[t]{4}{*}{1} & \multicolumn{3}{|c|}{ Duration of hospital stay (days) } \\
\hline & $<2$ & 12 & 12 \\
\hline & $2-5$ & 77 & 77 \\
\hline & $>5$ & 11 & 11 \\
\hline \multirow[t]{3}{*}{2} & \multicolumn{3}{|l|}{ Vault site infection } \\
\hline & Present & 1 & 1 \\
\hline & Absent & 99 & 99 \\
\hline \multirow[t]{5}{*}{3} & \multicolumn{3}{|c|}{ Postoperative complications* } \\
\hline & Bladder injury & 2 & 2 \\
\hline & Bowel injury & 0 & 0 \\
\hline & $\begin{array}{l}\text { Vascular complica- } \\
\text { tions }\end{array}$ & 0 & 0 \\
\hline & Adhesions & 42 & 42 \\
\hline \multirow[t]{3}{*}{4} & Need for resuturing & & \\
\hline & Present & 3 & 3 \\
\hline & Absent & 97 & 97 \\
\hline
\end{tabular}

${ }^{*}$ Adhesions is to mobilize the bladder and secure the uterine vessels. This is followed by separating the uterus and cervix from the vaginal apex and removal of the uterus. The vaginal cuff is then closed and the port site is also closed. Ideally, the procedure does not take beyond 60 minutes and in certain situations, there could be risk factors that predispose to intraoperative and postoperative complications which may directly or indirectly delay the duration of the procedure. ${ }^{7}$

Our study was carried out among 100 women of the reproductive age group of which $40 \%$ of the woman were overweight and the majority (80\%) were multipara. Fibroid uterus was the most common indication for laparoscopic hysterectomy (39\%). The history of previous surgeries was almost nil in the majority of the patients (48\%). In our study, the majority of the patients underwent the procedure within 60-120 minutes (70\%) and the duration of hospital stay was approximately 2-5 days in $77 \%$ of the participants. Our study observed a statistically significant relationship between parity and the complications of the surgery including the duration of the surgery and duration of hospital stay. It was observed that multiparous women had an increased risk of prolonged surgery (81.4\%) compared to nulliparous women and primi. Similarly, multiparous women had an inadvertently increased duration of hospital stay for more than 5 days compared to nulliparous women and primi. The observed differences were statistically significant ( $p$ value $<0.05$ ).

A few studies have been carried out to assess the factors which influence the success of laparoscopic hysterectomy. In a study

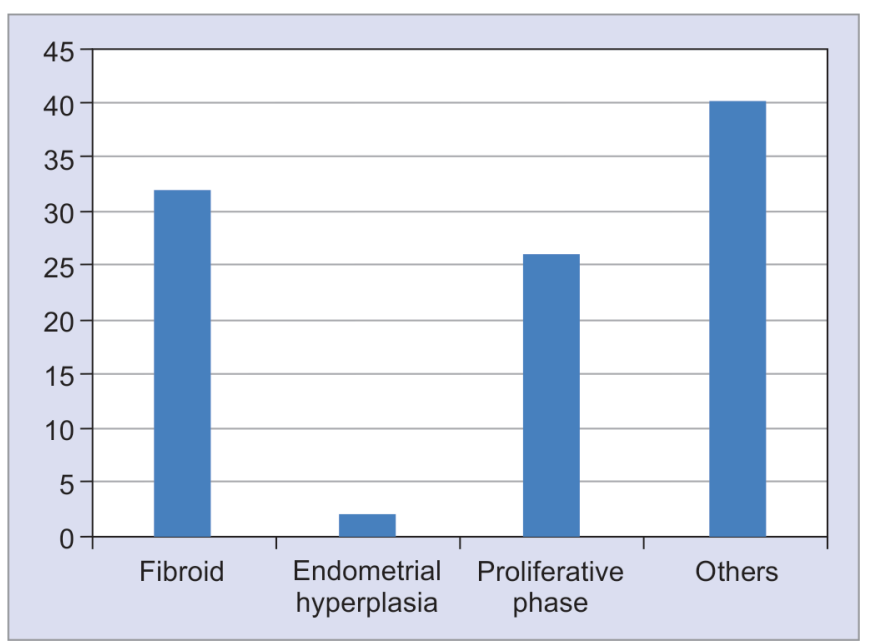

Fig. 1: Histopathology findings of hysterectomy specimens

Table 4: Association between parity and surgical outcomes

\begin{tabular}{|c|c|c|c|c|c|c|}
\hline \multirow[b]{2}{*}{ S. no. } & \multirow[b]{2}{*}{ Outcome } & \multicolumn{3}{|c|}{ Parity } & \multirow[b]{2}{*}{ Chi-square } & \multirow[b]{2}{*}{$p$ value } \\
\hline & & Nulliparous & Primi & Multiparous & & \\
\hline \multirow[t]{4}{*}{1} & \multicolumn{6}{|c|}{ Duration of surgery (in minutes) } \\
\hline & $<60$ & $3(12)$ & $3(12)$ & $19(76)$ & 11.407 & 0.022 \\
\hline & $60-120$ & $0(0)$ & $13(18.6)$ & $57(81.4)$ & & \\
\hline & $>120$ & $1(20)$ & $0(0)$ & $4(80)$ & & \\
\hline \multirow[t]{4}{*}{2} & \multicolumn{6}{|c|}{ Duration of hospital stay (days) } \\
\hline & $<2$ & $0(0)$ & $5(41.6)$ & $7(58.4)$ & 14.034 & 0.007 \\
\hline & $2-5$ & $2(2.6)$ & $11(14.3)$ & $64(83.1)$ & & \\
\hline & $>5$ & $2(18.2)$ & $0(0)$ & $9(81.8)$ & & \\
\hline
\end{tabular}


done by Krentel and De Wilde, the average duration of surgery was 194 minutes which was higher compared to our study findings. However, the increased duration of surgery was directly related to the parity of the woman. ${ }^{3}$ In another study done by Shushan et al., the mean duration of surgery was 76.9 minutes, similar to our study. Similarly, intra-abdominal findings including adhesions were present in around the 23 cases, similar to our study. ${ }^{8}$

Laparoscopic hysterectomy proves to be challenging in certain situations involving the woman's characteristics including obstetrics history and physiological profile. In conditions where there is a bulky uterus, access to uterine vessels is sometimes difficult and in such situations, it is advisable to take the uterine vessels up high initially to secure the blood supply to the upper uterus and then gradually work down toward a lower segment. In severely distorted anatomy, especially in multiparous women, it is essential to consider entering the retroperitoneum as early as possible. This may be done by beginning at the round ligament. ${ }^{7}$

\section{ConCLUSION}

Laparoscopic hysterectomy is said to have potential advantages in terms of ease of access and minimally invasive procedure with mild complications. Certain inherent situations of women make it challenging. It may be considered that the woman's profile in terms of their obstetric history, body mass index, etc., may be considered preoperatively before deciding on performing a laparoscopic hysterectomy. However, there are several incidences where laparoscopic hysterectomy has been converted in to open abdominal hysterectomy. This may not be suitable in most situations as the entire purpose of ease of surgery is lost in such situations. It is essential to develop a scoring mechanism by which each case can be selected or rejected for laparoscopic hysterectomy considering various parameters. This may be carried out by further exploratory research on identifying the key factors which influence the success of the procedure.

\section{Ethical approval}

Obtained

\section{References}

1. Ashokkumar J, Roopa MS. Clinical profile of patients undergoing laparoscopic assisted vaginal hysterectomy/total abdominal hysterectomy. Int J Clin Obstet Gynecol 2018;2(1):75-77.

2. Puntambekar SP, Wagh GN, Puntambekar SS, et al. A novel technique of total laparoscopic hysterectomy for routine use: evaluation of 140 cases. Int J Biomed Sci 2008;4(1):38-43.

3. Krentel H, De, Wilde RL. Factors for a successful laparoscopic hysterectomy in very large uteri. Case Rep Med 2017;2017:1637472. DOI: 10.1155/2017/1637472.

4. Chen B, Ren DP, Li JX, et al. Comparison of vaginal and abdominal hysterectomy: a prospective non randomized trial. Pak J Med Sci 2014;30(4):875-879. DOI: 10.12669/pjms.304.4436.

5. Aziz N, Kallur SD, Nirmalan PK. Implications of the revised consensus body mass indices for Asian Indians on clinical obstetrics practice. J Clin Diagn Res 2014;8(5):OC01-OC03.

6. Washington JL. Laparoscopic supracervical hysterectomy compared with abdominal, vaginal and laparoscopic vaginal hysterectomy in a primary care hospital setting. JSLS 2005;9(3):292-297.

7. Einarsson Jl, Suzuki Y. Total laparoscopic hysterectomy: 10 steps towards a successful procedure. Rev ObstetGynecol 2009;2(1):57-64.

8. Shushan A, Mohamed H, Magos AL. How long does laparoscopic surgery really take? Lessons learned from 1000 operative laparoscopies. Hum Reprod 1999;14(1):39-43. DOI: 10.1093/ humrep/14.1.39. 